\title{
Correction to: Implementing a real-time image captioning service for scene identification using embedded system
}

He-Yen Hsieh ${ }^{1} \cdot$ Sheng-An Huang ${ }^{1}$ • Jenq-Shiou Leu ${ }^{1}$

Published online: 31 March 2021

C) Springer Science+Business Media, LLC, part of Springer Nature 2021

Correction to: Multimedia Tools and Applications (2020) https://doi.org/10.1007/s11042-020-10292-y

In the original publication of this article, the captured corresponding author was incorrect. The original article has been corrected.

Publisher's note Springer Nature remains neutral with regard to jurisdictional claims in published maps and institutional affiliations.

The online version of the original article can be found at https://doi.org/10.1007/s11042-020-10292-y

\section{Sheng-An Huang}

M10802122@mail.ntust.edu.tw

He-Yen Hsieh

M10502103@mail.ntust.edu.tw

Jenq-Shiou Leu

jsleu@mail.ntust.edu.tw

1 National Taiwan University of Science and Technology, Taipei City, Taiwan 